\title{
CORPOREIDADE, MOVIMENTO, PLASTICIDADE NEURONAL E MATURIDADE ATIVA ${ }^{1}$
}

\author{
"Ter um corpo é condição de existência (...) \\ Ser um corpo, é condição de humanidade.”
}

Gonçalves, 1997.

Clézio J.S. Gonçalves ${ }^{2}$ Luciana de Meneses Coelho ${ }^{3}$

Resumo:

Nos dias de hoje existe uma perda das referências do indivíduo como alguém possuidor de qualidades únicas. A padronização de gestos e condutas faz com que muitos não reconheçam suas sensações como legítimas buscandose adequar a um modelo dos Meios de Comunicação Social (MCS). Este texto representa uma proposta de reflexão a respeito das possibilidades de desenvolvimento do cérebro humano através de atividades de movimento, de sensibilidade e percepção do corpo para a chamada terceira idade como forma de aprendizagem, aperfeiçoamento contínuo e exercício de suas potencialidades bem como cidadania.

Palavras-chaves: Aprendizagem; Movimento; Cérebro

\section{Abstract:}

Nowadays a loss of the references of the individual exists as somebody possessor of only qualities. The standardization of gestures and behaviors makes with that many do not recognize its sensations as legitimate searching to adjust to a model of the Social Mass Media (SMM). This text represents a proposal of reflection regarding the possibilities of development of the human brain through activities of movement, of sensitivity and perception of the body for the call third age as form of learning, continuous perfectioning and exercise

${ }^{1}$ Este texto reúne idéias apresentadas no Seminário promovido pelo Instituto do Câncer e Instituto de Psicologia Descobre-te a Tempo e desenvolvidas em dissertações de mestrado apresentadas pelo autor na Universidade Federal de Santa Maria e na Universidade Federal do Rio Grande do Sul.

${ }^{2}$ Mestre em Pedagogia do Movimento Humano pelo Centro de Educação Física e Desporto da UFSM, RS, e em Educação pela Faculdade de Educaçăo da UFRGS.

Estud. interdiscip. envelhec., Porto Alegre, v.3, p.123-147, 2001. 
of its potentialities as well as citizenship.

Key words: Learning; Movement; Brain

\section{Introdução}

Vamos iniciar este texto com duas frases para refletir-se a respeito. Primeiramente ". . . palavras diferentes, significam coisas diferentes." (Gonçalves, 1998, p.74). Assim, mesmo palavras que possuam sinônima, dependendo do contexto em que estão inseridas, assumem significados completamente diferenciados. É uma questão que parece elementar e óbvia, porém a eficiência de uma comunicação através da linguagem (em suas diferentes manifestações) depende desta compreensão. Em segundo lugar vamos refletir sobre uma questão que diz respeito ao cotidiano imediato de qualquer ser humano, ou seja, todos nós existimos porque estamos neste universo mediante à presença concreta de nosso corpo e/ou organismo. Em outras palavras, existimos graças a mediação de nossos corpos. Existir como seres que interagem com o mundo ao seu redor através desta mediação de nossos organismos. As palavras que vão surgindo neste texto, apesar de, primeiramente estarem na minha mente somente tornam-se manifestação concreta para outros mediante a este milagre de transformação de pensamentos através das ações musculares dos meus dedos no teclado. Ou será que alguém consegue tornarse presença concreta sem a mediação deste nosso organismo?

É importante destacar que a análise que realizaremos buscará princípios baseados na ciência, enquanto forma de também conhecer o mundo. Apesar de todos os erros históricos que a ciência já cometeu, ela é de longe o acervo mais confiável ao qual podemos consultar para a resolução de problemas. A humanidade não chegou até o estágio de desenvolvimento baseada apenas no senso comum. A ciência contribuiu significativamente para este avanço. Se ficássemos a depender do senso comum, talvez ainda estar-se-ia a pensar que o sol gira em torno da terra e conforme Sagan (1996, p.23) “. . . ainda se estaria a acreditar que gnomos, além de lindos objetos de decoração, realmente possuem um poder fantástico de alterar o rumo de nossas vidas." Uma das missões da ciência é pesquisar, descobrir o que existe além das aparências que os fenômenos apresentam. Auxiliar assim a compreender a realidade que nos 
rodeia para além de suas manifestações visíveis, onde muitas vezes ocultam-se processos fundamentais para a compreensão da mesma. A difusão das idéias em ciência de forma acessível à comunidade em geral é uma responsabilidade a qual a universidade não pode eximir-se. Uma das limitações que um senso comum muitas vezes apresenta é a de encerrar as diferentes manifestações da realidade em conceitos reducionistas perdendo-se assim a riqueza multidiferencial que esta apresenta. Desta forma uniformizam-se complexas situações em elementos simplistas, mutilando-se suas características mais peculiares que representam seus aspectos particularizados, homogeneizando-se num mesmo conceito elementos tão distintos que perde-se os aspectos de identidade e essência dos mesmos. Perde-se também assim a capacidade de ". . . maravilhar-se com o mundo." (Garder, 1995, p.17), de perceber os inúmeros pequenas maravilhas que somos brindados dia-a-dia.

Alguns destes aspectos também dizem respeito aos nossos organismos, nossos corpos, suas capacidades de movimento, de adaptação e exploração do meio ambiente e ao fantástico surgimento dos atos de falar, ler e escrever. Na escala evolutiva são etapas diferentes e progressivas na história da humanidade. O potencial que estes atos tão cotidianos representam na história de formação de cada indivíduo ainda é tema de pesquisa que não esgotou-se nos grandes centros investigadores pelo mundo.

Afirmamos alguns parágrafos acima que existimos pela mediação de nossos organismos. Porém, “. . . sentir o próprio corpo.” (Gonçalves, 1998, p.19) envolve uma sensibilidade mais aguçada. Sensibilidade esta que parece estar ausente do contexto que a contemporaneidade social envolve os seres humanos neste final de milênio. Assim, qualquer um de nós pode ". . . existir uma vida inteira, sem nunca perceber, sentir e ter consciência do próprio corpo.” (grifo nosso). Porém, se existe uma preocupação com a qualidade de vida nos seus aspectos mais amplos é bom começar a se perceber mais profundamente as trocas de mensagens/informações que este nosso corpo/organismo realiza e recebe quotidianamente.

Na maioria das vezes, as pessoas tomam consciência de suas sensações e percebem seus organismos quando, no limite de suas capacidades, este lhes envia sinais de aviso, algumas vezes chegando tarde demais. Nossos corpos/

Estud. interdiscip. envelhec., Porto Alegre, v.3, p.123-147, 2001. 
organismos são estruturas concretas que convivemos dia-a-dia como se fosse um repositório de algo distintivo que nos faz humanos (um eu, um ego, um self, um inconsciente, etc. - como se houvesse um "eu" em algum lugar e um corpo receptáculo em outro lugar -herança da tradição cartesiana ainda presente hoje em dia). Por isto na maioria das vezes não se presta atenção nas mensagens que ele nos envia a todo o momento. Talvez aqui caiba um alerta para os menos avisados. Quando, por exemplo, ficamos sabendo que aconteceu um infarto do miocárdio, um acidente vascular cerebral, um enfisema pulmonar de forma repentina com alguém que conhecemos. É bom esclarecer que estes incidentes nunca são repentinos... eles são resultado de anos e anos de preparação com atitudes displicentes em relação as necessidades que nosso corpo necessita e aos sinais que o nosso organismo nos remete. Nosso corpo é capaz de profundas transformações para suportar as alterações de ritmos e esforços que o submetemos. Ele é fiel e dedicado às nossas vontades, mesmo quando elas representam prejuízos para seu equilíbrio e organização. Porém ele não é eterno e ilimitado. Pelo contrário, necessita de constantes momentos onde possa renovar suas energias e restaurar um equilíbrio necessário que ás vezes fica esquecido no ritmo vertiginoso com que a vida contemporânea suga de seus cidadãos.

O título deste texto pode representar uma tautologia no universo da ciência contemporânea. Uma vez que, as pesquisas desenvolvidas na neurologia e ciências cognitivas apontam para uma compreensão cada vez maior nas relações da mente e do corpo, dos processos biológicos e psicológicos nas suas dimensões envolvendo o movimento é claro que isto afeta de modo imediato o processo de envelhecimento do ser humano e os respectivos conceitos na sociedade com relação a esta temática. Entretanto, apesar de toda pesquisa científica nos grandes centros de estudos sobre aprendizagem, cérebro, mente etc., estes avanços ainda não chegaram até o cotidiano da maioria das pessoas como possibilidades de alcance possível. Ou seja, na pesquisa que realiza-se no momento presente cada vez mais aponta-se para a necessidade de compreensão dos processos de percepção do corpo e de elaboração de processos mentais como elementos integrados em contínua reconstrução, mas estas necessidades de trabalho integrador e potencializador estão distantes como 
alternativas possíveis.

Por mais paradoxal e ofensivo que possa parecer a espíritos mais sensíveis o que estamos querendo dizer, em outras palavras, é exatamente isto, que o corpo não é descoberto nas suas capacidades de aprender/sentir e encontrase excluído como potencializador nas estratégias de experiencias cotidianas da maioria das pessoas.

\section{Corpo, Corporeidade, Movimento}

Em primeiro lugar vamos definir algumas questões relativas ao item "corporeidade". Como afirma Santos (1994, p.74) em tempos pós-modernos “. . . as pessoas voltam-se para as questões relativas à corporeidade como forma de encontrarem referências seguras de identidade." A palavra corporeidade nos lembra em sua raiz semântica a palavra "corpo".

Tais palavras remetem uma reflexão sobre a natureza da experiência corporal sensível e imediata, seus desdobramentos na construção da subjetividade do sujeito que conhece. Neste sentido pode-se perguntar: "De que corpo se está falando?" Este é o primeiro obstáculo a se enfrentar na discussão desta temática: mas afinal de que corpo se está falando (ou escrevendo)? Uma das primeiras tentativas que se estabelece no ser humano para superar este obstáculo é estabelecida com relação à linguagem na tentativa de comunicar-se com outrem na expectativa que os termos que estão sendo usados tornam-se compreensíveis em sua plenitude por todos os demais que ouvem ou lêem.

Através dos tempos, o ser humano buscou construir palavras que expressem cada vez melhor suas idéias e seus sentimentos, ampliando a sua capacidade comunicativa na esperança de ser melhor compreendido pelos seus interlocutores. Traduzir a experiência sensível do próprio corpo é uma destas tentativas as quais a humanidade vem tentando configurar e construir palavras até o presente que consigam dimensionar esta experiência.

Isto representa um desafio pois significa encerrar dentro de uma linguagem verbal e/ou escrita a dimensão da experiência de uma vivência, que são dimensões completamente diferentes uma da outra. Ao longo dos séculos a construção social da linguagem, em suas diferentes manifestações 
tornou-se um meio para a comunicação humana por excelência. Linguagem que, por natureza é a construção de signos ou símbolos em que procura-se comunicar a outrem a dimensão de uma realidade vivida enquanto experiência. Entretanto, quando esta comunicação diz respeito às experiências vivenciadas pelo próprio corpo, inúmeras dificuldades de delimitação e clareza através das palavras começam a acontecer. Estabelece-se um paradoxo... como posso ter certeza de que o outro está compreendendo a minha experiência vivencial? Nietzsche, já nos seus primeiros escritos adverte para o quanto há de engano na crença de que os signos verbais e escritos possam dar conta da complexidade de qualquer experiência no seu aspecto vivencial. Escreve:

"Todo conceito nasce por igualação do não igual. Assim como é certo que nunca uma folha é inteiramente igual a uma outra, é certo de que o conceito de folha é formado por arbitrário abandono dessas diferenças particulares por esquecer-se do que é distintivo, e desperta-se então a representação como se na natureza além das folhas houvesse algo que fosse "folha" segundo a qual todas as folhas fossem tecidas.”(Nietzsche apud Naffah, 1993, p.18).

Pode-se dizer que corpo é uma palavra que qualquer pessoa tem algum tipo de opinião formada a respeito e algo para falar. Pensamos que aí resida uma questão pontual... falar sobre o corpo...talvez mais do que falar fosse necessário vivenciá-lo. Talvez um erro comum que tem acontecido seja o de compreender-se que a linguagem verbal representa apenas a única forma de comunicar...é uma forma mas não a única.

Algumas questões pertinentes a respeito deste tema já são suficientes para acender uma polêmica: O que cada indivíduo sabe sobre o próprio corpo, sua experiência sensorial própria e a construção da sua subjetividade humana a partir das experiências particularizadas de movimento? Os tempos atuais refletem um comportamento mais tranqüilo, natural e saudável com relação ao próprio corpo ou manifestam-se como uma normatização e doutrinação de movimentos e atitudes padrões com os quais limitam-se as suas capacidades de resposta? Como a vivência deste corpo e da sexualidade se apresentam no 
universo cotidiano? Abordar-se as questões relativas ao corpo e sua experiência do sensível, também se está abordando as questões da sexualidade, uma vez que estas questões tornam-se relevantes na medida em que dizem respeito ao tipo de concepção que existe no cotidiano com relação ao tema corpo e sexualidade.

Voltando-se às questões da linguagem quando alguém consegue se expressar, utilizando-se um termo que considera adequado para as circunstâncias experimentadas, de certa forma este sujeito sente-se mais tranqüilo pois entende que aquilo do qual fala e/ou escreve está sendo compreendido, em sua maior parte, pelos que estão escutando e/ou lendo. Atento aos limites da linguagem que Nietzsche coloca anteriormente, Santin (1993) salienta que pode-se perceber que existe alguma facilidade na comunicação de alguns conceitos como "terra" ou "fogo". Diz-se alguma facilidade, porque ainda assim existem diversos tipos de terra e de fogo, em diferentes compreensões culturais. Portanto o nosso conceito, apesar de compreensível, ainda seria restrito e limitado em sua descrição. Mas, para tranqüilidade do comunicador, apesar das inúmeras diversidades culturais, ele ainda pode de certa forma ser compreendido, pois são conceitos que pode-se chamar dizer são plenamente identificados pela maioria das pessoas.

"Corpo" também é, de certa forma um conceito material. No âmbito da Biologia (Maturana, 1987), não é difícil, enumerar uma série de características comuns à espécie. Se pedirmos para qualquer pessoa descrever estas características, poucas não conseguirão enumerá-las a contento. Entretanto quando vai definir-se individualmente a experiência corporal e as sensações que dela advém, em termos compreensíveis a outrem, encontra-se obstáculos quanto à sua definição e compreensão (Humphrey, 1995). As dificuldades são inúmeras... pois se está comunicando uma experiência vivencial e pessoal, portanto de que corpo se fala?

Seria um corpo apenas "material” constituído por matéria orgânica comum a todos os demais corpos? Mas o corpo humano também possui uma consciência de si e do mundo que lhe confere significados diferenciados de outras espécies biológicas. De um corpo que percebe? De um corpo que sente? Mas outras espécies também percebem o meio circundante. De um corpo que 
conhece? Talvez aqui, nos itens consciência e conhecer comece-se a tratar-se mais de um corpo humano.

Seria de boa medida deixar-se que o corpo fale do próprio corpo afirmam Santin (1987) e Bruhns (1984). Assim a linguagem escrita, diferentemente da linguagem corporal, é uma sequiência de códigos e sinais que procura ser compreensível para terceiros, e, por mais pormenorizada que ela seja, sua representação do "real" ainda será um limite. Deixar que o corpo fale do próprio corpo é ouvi-lo no exato instante que ele se manifesta, nas situações concretas que acontecem e se esgotam naquele instante, conferindo-lhe um status de originalidade significativo, impossível de ser reproduzido posteriormente na sua totalidade (Ghiraldelli, 1990).

A partir do séc. XX inicia-se a procura de outras palavras que possam melhor delimitar os elementos diferenciadores deste "corpo" do ser humano, que, ao mesmo tempo que possui elementos tão comuns presentes na natureza, também possui características que o diferenciam e o destacam do restante do mundo vivo.

Nos últimos anos o termo "corporeidade" tem sido bastante citado, inclusive com linhas pesquisa em Programas de Pós-Graduação e que na afirmação de Santin (1987, p. 58) “ . . . a humanidade do homem se confunde com a corporeidade.” Para este autor o corpo e os seus movimentos estão no centro de toda e qualquer possibilidade expressiva e sendo o corpo uma entidade que manifesta-se do próprio humano ele possui uma intencionalidade que precisa ser compreendida. Nas palavras do mesmo autor:

"O homem é essa realidade que se manifesta e se expõe diariamente às óticas abrangentes nos campos perceptivos, através da infinidade de suas possibilidades expressivas, instauradas pela dinâmica da corporeidade. O homem é uma autoconstrução corporal." (Santin,1987, p.61).

O uso deste termo buscou construir uma linguagem que ultrapassasse a divisão do corpo e da mente como instâncias distintas e separadas. Desta forma a consciência não seria apenas uma proprietária do corpo como forma dele dispor quando achasse mais conveniente, como se fosse apenas locadora de 
um corpo, mas sim, “. . . manifestaria-se através de um corpo.”, (Gonçalves,1997, p.16) carregando nesta manifestação a história dos elementos orgânicos constitutivos deste organismo e que afetariam, as mais variadas formas desta comunicação.

Entretanto, como toda e qualquer palavra que busca delimitar uma realidade, o termo "corporeidade" também começou a correr os meios acadêmicos a ponto de falar-se de uma corporeidade e pouco compreendê-la no seu sentido vivencial e concreto. Santin (1993) alerta que os manuais científicos fornecem definições inteligíveis sobre o domínio científico da corporeidade mas isto não significa a compreensão de suas dimensões vivenciais. A etimologia mostra a raiz latina do termo que deriva-se do corpo, que por sua vez, significa a parte material dos seres animados, colocando-nos mais uma vez na oposição mente $\mathrm{x}$ corpo.

O próprio Santin(1993) afirma:

A corporeidade é acima de tudo, uma presença, uma manifestação, uma visibilidade, talvez dito com maior precisão uma fisionomia. A corporeidade se estende para além dos limites da Física e da Biologia. Ela alcança a esfera da consciência e não exclui a possibilidade de transcendência. Podemos afirmar com certa segurança que a corporeidade é a condição humana, é o modo de ser do homem (Santin, 1993, p. 13).

Entretanto, apesar da importância destacada pelo autor, o termo corporeidade , devido ao seu excessivo uso e conseqüente reducionismo de concepção corre o risco de encontrar-se no domínio da definição racional e técnica, ao ponto de hoje falar-se de uma corporeidade e muito pouco vivenciála. Nas palavras do autor (Santin, 1993) “. . . a corporeidade do corpo pode não coincidir com a corporeidade do pensamento racional.” (p.63).

Já Merleau Ponty (1973) situa a corporeidade como a dimensão do homem como ser no mundo. Uma dimensão cuja compreensão do seu significado é fundamental na busca de uma vida profundamente humana. Desta forma, percebe-se que, apesar das intenções dos autores buscarem dar um sentido mais amplo ao termo "corporeidade" ainda corre-se o risco que no seu 
uso cotidiano, o mesmo venha ser mal-interpretado ou até mesmo reduzido em sua dimensão mais significativa. Sem contar que, dependendo do tipo de inferência filosófica o conceito "corporeidade" pode ganhar uma conotação "transcendente" e atingir uma esfera metafísica cujos desdobramentos não são a intenção deste artigo. O que deseja-se construir é uma reflexão que aponte a necessidade de concretude para a elaboração de alternativas viáveis potencializadoras deste nosso organismo que interage com o meio.

Para Maudire (1988) existe na sociedade uma instrumentalização do corpo, onde o mesmo tem a tarefa de apenas desempenhar tarefas com a máxima eficiência e produtividade. Esta condição empobrece as potencialidades do humano que se manifestam pelo corpo. Segundo a mesmo autora "É o trabalho corporal que vai abrir-me a via de mudança, um trabalho de expressão do corpo, portanto de auto-expressão.” (Maudire, 1988, p. 29).

Neste sentido "corpo" e/ou "corporeidade" não significariam apenas um único indivíduo, mas um sistema de complexidades e inter-relações consigo e com os demais que neste processo de tangências relacionais, construir-se-ia um sistema de compreensão, de relação e de intervenção no mundo. Necessitase para a construção do sujeito, de um outro e de um meio.

O importante também é perceber-se que cada indivíduo constrói a sua própria imagem corporal (Feldenkrais,1978 ). A partir disto esta imagem pode corresponder ou não à sua realidade concreta e imediata. Se as percepções que os indivíduos constróem de si correspondem à realidade das evidências que se apresentam do mundo, tem-se então um ser humano consciente de si e do meio que o cerca com um significativo potencial de intervenção. Por isto, um fato que merece destaque é o de que a imagem corporal não surge apenas das experiências existenciais da vida pessoal (Feldenkrais, 1988). Se isto fosse verdade a interação e a comunicação social seriam quase impossíveis. Por isto as primeiras imagens conscientes de corpo que cada indivíduo constrói está ligada aos modelos impostos pelos valores culturais vigentes.

Por isto, o senso comum tem para si que o fato de as funções vitais do corpo ao desenvolverem-se naturalmente não necessitam de maiores interferências conscientes de cada um. Assim, são lhes dadas poucas atenções no seu processo evolutivo como indivíduo e como espécie, a não ser no 
momento em que aparecem problemas (Saviani, 1987). O estar vivo consiste essencialmente na interação de corpos, internamente consigo mesmos e com o seu mundo-ambiente. Importa para este projeto a dificuldade de sentir um corpo, diferentemente, talvez porque já nos foram indicados de mil maneiras diferentes que temos um corpo (Santin/1987/1994, Morais/1993, Grupe,1978). Pode-se afirmar que apesar da existência de um corpo "geral” caracterizável a partir de certos dados e generalizável ao ser humano (cf. algumas ciências), também existe sempre o corpo concreto de cada um que se constrói na história pessoal que necessita de compreensão e adequação.

Nesta perspectiva não cabe mais buscar-se um conceito único e abrangente procurando-se depositar nele todos os corpos que encontra-se pelo caminho.

\section{Plasticidade Neuronal, Autopoiése e Experiência do Próprio Corpo}

Maturana (1991) apresenta um conceito a respeito do ser vivo que merece ser analisado. Diz o autor que a característica básica de qualquer ser vivo (incluindo-se aí o ser humano) é a sua autopoiése como unidade capaz de reorganização interna (Morin,1994) para atuar no meio externo através de um acoplamento estrutural. A descrição pode parecer complexa mas fornece elementos simples para uma análise

Pode-se realizar um pequeno exercício (Gonçalves, 1997, p.77) fazendo uma experiência com uma ação que realizamos todos os dias para ilustrar e exemplificar esta afirmação. Todos nós cruzamos nossos dedos nas mãos. Vamos realizar esta tarefa. Faça você mesmo ou peça para alguém que cruzem os dedos das mãos de forma entrelaçada como é sempre seu hábito. Após, solicita-se que fechem os olhos e façam o mesmo gesto, porém, invertendo-se o sentido do cruzamento de todos os dedos. Pode-se realizar a mesma tarefa com o gesto de cruzar os braços. Em seguida, encaminha-se pergunta-se e reflexões sobre as diferenças entre as sensações de uma posição e outra e quais as percepções no próprio organismo. A maioria dos relatos dos alunos em inúmeras vezes que este exercício foi realizado, situam uma sensação de "desencaixe", "falta/sobra de dedo", "estranho", "parece errado", etc. Depois destas manifestações solicita-se que os mesmos façam a mesma tarefa olhando 
para as próprias mãos e pergunta-se "Existe uma outra pessoa segurando as suas mãos?", apesar da surpresa com a questão todos afirmam que não existe uma outra pessoa, apesar da sensação dar a impressão que parece existir um outro indivíduo a segurar nossas mãos. Este exercício caracteriza-se por ser uma constatação do "estranhamento" com relação ao próprio organismo.

Então, não estamos nos sentindo estranhos com um outro. Mas estamos nos sentindo estranhos com o nosso próprio corpo e com nossa própria sensação. Ainda mais, sentimo-nos estranhos por fazer diferente o que estamos acostumados por hábito, a fazer do mesmo jeito, apesar de termos potencial para fazer de outra maneira. Este é o ponto de nossa autopoiése. Nossa própria organização como organismo faz com que observemos de uma forma a qual foi construída através de nossa história de interações. Porém, no caso das mãos, eu tenho a possibilidade de realizar de inúmeras outras formas o ato de cruzar os dedos e as mãos... mas o fazemos sempre do mesmo jeito. Ao realizar sempre do mesmo jeito, esta é uma construção de nosso sistema nervoso nas suas interações sinápticas.

Para avançar-se nesta reflexão, vamos analisar um pouco mais detidamente esta relação entre a estrutura que chama-se cérebro e o que chamamos por mente. Este é uma complexa estrutura existente - talvez a mais complexa no universo - é um objeto definido conceitualmente: esta localizado dentro da caixa craniana e pode ser visualizado, tocado e manipulado. É composto de substâncias químicas, enzimas e hormônios que podem ser medidos e analisados. Sua arquitetura é caracterizada por células neuronais, vias neurais e sinapses. Seu funcionamento depende de neurônios, os quais consomem oxigênio, trocando substâncias químicas através de suas membranas, e mantendo estados de polarização elétrica interrompidos por breves períodos de despolarização num processo contínuo.

Mas... como encontramos os nosso processos mentais que possibilitam estas reflexões? Como se estabelece uma mente que me possibilita a percepção de minhas sensações e consciência de mim mesmo? Mesmo após vários séculos de reflexões filosóficas, dedicação intensa à pesquisa cerebral neste século e notáveis avanços no campo das neurociências nesta última década, o conceito de mente ainda permanece obscuro, controverso e difícil definição nos limites 


\section{de nossa linguagem.}

Uma visão fortemente defendida desde os tempos da Grécia antiga e ainda hoje muito presente na organização de mundo de milhões de seres humanos, é a de que a mente é uma entidade separada do corpo. Esta concepção tem raízes históricas nas teorias que determinaram hipóteses dualísticas da função cerebral, as quais admitiam que o cérebro pode ser visto mecanicamente, mas que a mente é uma entidade com uma característica física não definida. Em tais teorias, a mente era vista como um sinônimo da alma, formando uma parte integrante da cultura religiosa prevalecente. René Descartes (1596-1650), perpetuou o dualismo mente-corpo de Platão (428-348 A.C.), separando filosoficamente a mente e o corpo. Ele estimulou o debate "Como a mente não-material influencia o cérebro e vice-versa ?". Suas idéias permearam visões filosóficas e cientificas até os presentes dias, mudando assim, a abordagem de pesquisa do problema do "eu". Desde que a mente e o cérebro passaram a serem vistos como entidades isoladas, as pesquisas nestas áreas foram, de maneira geral, inerentemente separadas. Bioquímicos têm se preocupado com mecanismos somáticos; psicólogos têm se esforçado com as propriedades subjetivas da mente; filósofos e teólogos trazem com eles o espírito e a alma

Definir-se a Mente seria uma tentativa de resgatar o que alguns chamariam de a essência do homem. A essência de uma pessoa como algo que emergiria da existência de funções mentais permitindo a ela pensar e perceber, amar e odiar, aprender e lembrar, resolver problemas, comunicar-se através da fala e da escrita, criar e destruir civilizações. Estas expressões estão estreitamente relacionadas ao funcionamento cerebral. Assim, sem o cérebro, a mente não possui condições de existir

As atuais pesquisas na neurociência tem entendido o cérebro e a mente como resultado da investigação experimental. Parece ser mais coerente e factível pensar-se que condutas e atitudes são dependentes da atividade fisiológica do cérebro e de nosso ambiente cultural. Nós se conseguirá ter conceitos se não existir um cérebro funcionante (no caso de por exemplo quando a atividade do cérebro é bloqueada por coma ou anestesia profunda), e não se pode compreender coisas que nós não aprendemos, ouvimos e experenciamos.

Ainda hoje, a maioria dos cientistas geralmente são relutantes em 
combinar trabalho experimental com filosofia, e geralmente rejeitam considerações de possíveis implicações psicológicas em seus estudos. Entretanto, alguns estudos neste campo começaram a aparecer. Na opinião do famoso neurofisiologista José Maria Delgado “. . . é preferível considerar a mente como uma entidade funcional destituída de implicações metafísicas e religiosas per se e relacioná-la somente à existência de um cérebro e à recepção de inputs sensoriais." Poucos neurocientistas, tais como o prêmio Nobel John Eccles, admitem que a mente é distinta do corpo, mas a maioria deles agora acredita que todos os aspectos da mente, os quais são freqüentemente equiparados com a consciência, provavelmente são explicados como resultantes do comportamento aprendido culturalmente e da química de células neuronais.

Se o cérebro tem explicado a mente, como explicar os eventos mentais como sendo causados pela atividade de um grande conjunto de células neuronais? Aos poucos os neurocientistas, têm começado a combater a idéia de que esta questão é puramente filosófica ou ilusória para ser estudada experimentalmente, e estão começando a abordar o problema cientificamente. Começaram a surgir evidências sobre o entendimento de possíveis mecanismos cerebrais que podem ser subjacentes à processos mais complexos na experiência e comportamento humano, tais como o fenômeno da consciência, atenção e pensamento.

Certamente, um dos mais notáveis exemplos para ilustrar a relação entre o cérebro e a consciência são os achados que assumem que existem "dois cérebros" em cada cabeça ou seja, cada hemisfério (cada metade do cérebro) é anatomicamente uma imagem em espelho do outro hemisfério, uma vez que a maioria das estruturas estão presentes em ambos os lados e se comunicam por feixes massivos de fibras. Funcionalmente, entretanto, cada hemisfério tem suas próprias áreas de especialização mental, um fenômeno chama-se de "lateralização cerebral". Por exemplo, o hemisfério esquerdo está mais envolvido com funções verbais e racionais, enquanto o hemisfério direito está relacionado com funções artísticas e visuo-espaciais. As fibras interconectantes exibem um papel importante na coordenação das atividades dos hemisférios; sua lesão pode levar o indivíduo a se comportar como se os dois hemisférios fossem responsáveis por duas consciências separadas, como foi inicialmente 
notado por R. Sperry (o qual foi consagrado com o prêmio Nobel por isso) Em outras palavras, se a "ponte" entre os dois hemisférios é destruída, um hemisfério não pode saber o que o outro está fazendo.

Outro achado significativo nas neurociências é a correlação de eventos mentais, tais como a aprendizagem, com alterações químicas e estruturais das células nervosas. Atualmente, sabe-se que no cérebro novos ramos neuronais crescem em resposta à diversidade cultural, isto é, ao treino e à experiência do dia-a-dia. Cada neurônio parece contribuir para muitos comportamentos e atividades mentais. Técnicas modernas estão agora começando a revelar como o cérebro tem conseguido a notável proeza da aprendizagem através da construção de novas sinapses e da plasticidade neuronal.

Neste conceito os neurônios, células-base da estrutura cerebral, possuem uma capacidade de reorganização contínua, conferindo uma plasticidade única ao cérebro através de suas experiências interativas com o meio ambiente. Assim a aprendizagem também influencia na organização do cérebro. Além disto Redes artificiais de neurônios sobre computadores estão ajudando a explicar a habilidade do cérebro em processar e reter informação. Também, as ciências cognitivas modernas, utilizam um vasto conjunto de técnicas novas, estão sendo capazes de estudar objetivamente muitos componentes do processo mental, tais como atenção, cognição visual. linguagem, imaginação mental, etc., e estão sendo correlacionadas com atividade neural por meio de imagem funcional computadorizada e estão agora abertas à investigação científica.

E o cérebro existe em um organismo que atua continuamente com o meio percebendo suas sensações internas e externas em um processo contínuo e ininterrupto onde cada ação e conduta é passível de inúmeras alternativas e possibilidades diferentes dependendo do tipo de interação histórica construída. Portanto as possibilidades de potencialização do cérebro passam pela tomada de consciência da experiência do organismo próprio como fonte de conhecimento.

Por isto a ênfase no termo "vivenciar" como forma de caracterizar um tipo de experiência é fundamental, pela simples razão de que a experiência corporal não deveria ser algo do qual apenas se fala ou escreve a respeito, mas significativamente uma experiência que se vivência e se comunica através de 
nossos comportamentos e atitudes, muitas delas não verbais. É importante destacar que, para perceber-se a vivência da experiência sensível é preciso num primeiro momento admitir-se a existência de um corpo que experimenta sensações. Sensações às quais seriam importante para cada indivíduo entrar em contato e principalmente nomeá-las. "A experiência sensível é algo que existe num corpo concreto com sensações e percepções. E um corpo que sente a sua experiência sensível e entra em contato com ela, no caso humano, é um corpo que deseja." (grifo nosso) E um corpo que deseja significa estar atento ao que acontece no momento presente e entrar em contato com uma força motivadora que anima os mais variados esforços humanos. Assumir o próprio desejo e nomeá-lo adequadamente, deveria ser uma atitude esperada de uma pessoa consciente das interações e responsabilidades com o seu meio.

Assim a aprendizagem altera a estrutura de nosso cérebro constantemente e não apenas em uma determinada época da vida. Finalmente, nós percebemos não somente o brilho e a fascinação exercida pelas funções mentais humanas, as quais são responsáveis pela criação e evolução de nossa sociedade, mas também a escuridão e o desespero das disfunções mentais, as quais afetam e destroem o ambiente interno e externo do ser humano. Também neste campo, os impressionantes avanços na neurociência e genética estão revelando as bases anatômicas, bioquímicas e hereditárias da esquizofrenia, mania, distúrbios afetivos e do humor, ansiedade, déficits intelectuais, distúrbios da memória e muitos outros bem como a fantástica influência do meio no surgimento destes processos

Assim, cada vez mais, se esta percebendo o que em séculos antes não era possível entender: o cérebro é complexo o suficiente para explicar os mistérios da aprendizagem, memória, emoção, criatividade, consciência, experiência vivencial e da loucura. Se nós concordarmos em pensar na mente como se ela fosse um conjunto de funções mentais, mais do que substância imaterial, será mais fácil continuar com os necessários estudos empíricos e então um progresso ainda mais substancial poderá ser feito não somente na busca para a natureza do homem como um indivíduo cognitivo, mas também no alívio das doenças mentais e no melhor entendimento de valores e concepções culturais as quais, ao longo dos séculos, têm trazido grandes prazeres - e aflições 
- à humanidade.

\section{Maturidade Ativa}

E o que todo este contexto tem a ver com o que chama-se hoje de terceira idade? Em primeiro lugar definir um período de vida como terceira idade implica na existência de um primeiro e de um segundo. E com os atuais avanços na medicina que tem prolongado a expectativa média de vida, parece que o tempo em anos da terceira idade já está superando as idades anteriores obrigando a discutir-se o nascimento de uma quarta idade.

O que deseja-se discutir são alguns mitos que são atribuídos a esta faixa etária em virtude das escassas pesquisas que são realizadas a respeito. Por exemplo:

a) em virtude da idade a atividade física é de apenas manutenção atualmente começam a surgir timidamente pesquisas sobre o desenvolvimento da capacidade física (dentro das capacidades peculiares de cada indivíduo) que apontam uma melhora diferenciada; b) mitos relativos a incapacidade de vivenciar a própria sexualidade -o que já foi contestado pelos próprios sujeitos além de não encontrar eco no que foi observado até o momento presente. E finalmente, o mito de que, em virtude da idade a maioria encontra-se incapaz de aprender.

Tal afirmativa somente encontra fundamento baseada em senso comum ou em preconceito pois a mesma não encontra-se amparada nas inúmeras pesquisas desenvolvidas até o momento. É certo, já comprovado em inúmeras pesquisas que os primeiros anos de vida são fundamentais na vivência de experiências que proporcionem possibilidades potenciais para o desenvolvimento e crescimento neuronal através da aprendizagem levando-se em conta que estes momentos nos acompanharão por toda a existência. Porém agora, aos poucos, começa-se também a investigar as possibilidades de continuidade deste processo de interação neuronal, apesar dos anos de vida que um indivíduo venha a ter. Mesmo que durante a adolescência as conexões do córtex cerebral começam a se estabilizar, elas entretanto não cessam. Como o cérebro recebe milhões de estímulos contínuos a cada segundo a tarefa de 
vigília e praticamente ininterrupta. Portanto o conceito que se discute hoje como derivado das mudanças tecnológicas de aprendizagem contínua e permanente encontra também substrato biológico na estrutura do sistema nervoso.

Assim o cérebro de qualquer pessoa continua em franca atividade. Porém, se o mesmo não for adequadamente estimulado em suas interações ele também não realizará as suas possibilidades de reconstrução plástica. É certo que, na terceira idade, os processos necessitem acontecer de forma mais lenta em virtude destas conexões mas isto não significa impossibilidade. Por isto prefere-se utilizar o termo maturidade ativa como definição de uma condição em que o processo de aprender é contínuo.

Hoje em dia é muito grande a oferta de atividades de lazer aos sujeitos da chamada terceira idade (aos quais nós assim iremos nos referir quando quiser-se fazer referência ao tipo de conceito adotado pelos mitos do senso comum) e estas envolvem as mais diferentes atividades tais como ginástica, alongamentos, yoga, massagens, relaxamentos, teatro, passeios, excursões, dança, caminhadas, etc. Que razões tem levado estas pessoas a procurarem estas alternativas? São, é claro, inúmeras desde aquelas de ordem motivacional e pessoal, quanto as de ordem de convívio em grupo.

Porém não se pode desconsiderar um aspecto importante neste fenômeno. A realização de atividades e de movimento por parte de qualquer sujeito gera uma série de alterações na química do organismo e consequentemente no cérebro. Uma das inúmeras substâncias produzidas nestes momentos é a endorfina, neuro-transmissor capaz de gerar sensações agradáveis e prazerosas que o organismo procura manter. Manter um fluxo de sensações agradáveis é uma conduta que qualquer sujeito procura manter. Por isto também esta é uma razão da procura pela oferta de atividades envolvendo o corpo e consequentemente a produção de inúmeras substâncias químicas neste ato.

Mas se a atividade ficar prescrita apenas no âmbito do fazer pelo fazer a repetição contínua de exercícios irá desenvolver no indivíduo uma necessidade de produção destas substâncias para a qual ele poderá dedicar a maior parte de seu tempo deixando de lado a atenção para os demais aspectos de sua vida. E isto é o que mais constata-se no desenvolvimento das inúmeras alternativas 
propostas para esta idade. Desta forma importa apenas o momento concreto de realização da atividade. Como se fosse um mundo criado à parte, um paraíso particular afastado do cotidiano do sujeito.

O que procura-se chamar a atenção é para o fato de que é possível potencializar-se cognitivamente esta faixa etária a fim de instrumentalizá-la como maturidade ativa, tanto física quanto cognitivamente apesar dos anos em idade. É claro que, dependendo do tipo de interações históricas que cada sujeito desenvolveu não se pode desenvolver um trabalho inicial envolvendo questões tão abstratas quanto formulações matemáticas de física quântica. Em virtude das limitações da deriva histórica que o sujeito apresenta começa-se a estimulação através de vivências sensoriais agrupadas com desafios cognitivos e vai-se gradualmente partindo de situações simples para situações cada vez mais complexas mantendo-se a dimensão vivencial sempre associada às reflexões de natureza cognitiva.

E por que trabalhar-se cognitivamente utilizando-se diferentes técnicas e linguagens? A capacidade do ser humano comunicar-se através da linguagem potencialmente exponencial e cada momento que é utilizada ocorre um verdadeiro milagre no sentido mais pleno. Como diz o cientista cognitivo Pinker:

"Ao ler estas palavras, você estará participando de uma das maravilhas do mundo natural. Pois você e eu pertencemos a uma espécie com uma característica notável; podemos dar forma a eventos nos cérebros de outras pessoas com extrema precisão...essa capacidade é a linguagem. Simplesmente por fazermos barulho com nossas bocas, podemos com confiança, fazer com que surjam novas combinações de idéias nas mentes de outras pessoas. Essa capacidade surge tão naturalmente que tendemos a esquecer quão milagrosa ela é." (1994, p.73)

Sendo esta capacidade exponencial da linguagem um aspecto da conduta humana é mais do que óbvio que este processo continue através dos anos em qualquer momento da vida de um sujeito que aprende. O simples desenvolvimento da atividade física tem um aspecto paradoxal... se um profissional desejar ele pode trabalhar os seus alunos como máquinas em busca 
de performance. $\mathrm{O}$ problema é que seres humanos não são apenas máquinas de resultados. Este é o paradoxo da atividade física posso lidar com o ser humano como máquina, ele responde e produz...mas ele é muito mais do que isto. Se movimento, a corporeidade trabalharem apenas com o componente de saúde do corpo e desconsiderar os aspectos cognitivos e subjetivos na construção do movimento, estar-se-á desrespeitando a capacidade mental de seus alunos e desconsiderando o esforço que a natureza fez para construir um organismo capaz de abstrações. Que tipo de abstrações são construídas numa aula de educação física? Ou será que como profissionais, realmente partilha-se da crença de que o movimento não influencia na construção das subjetividades humanas? Se o movimento é mera repetição, porque trabalhar com um organismo capaz de realizar operações mentais?

Senão agir-se assim, nesta busca de um trabalho integrado corre-se o risco de manter estes sujeitos num estado primário de sensorialidade primitiva que, por ser envolvente na produção sensações prazerosas, limita o indivíduo à vivência de um espaço restrito de paraíso particular mantendo-o num estado infantilizado e incapacitando-o para o exercício de sua autonomia e cidadania. Partir-se para o outro extremo e exigir uma condição de abstração que os mesmos ainda não possuem em virtudes de suas derivas históricas por não terem contado com a interação/estimulação adequada no momento preciso é abandoná-los ao ostracismo e determinismo de suas condições por não desenvolver suficiente sensibilidade para realizar os desafios de forma adequado aos ritmos diferenciados a isto, perceber o próprio corpo?

Esta pergunta torna-se desconfortável, na medida que as pessoas vão desenvolvendo seus organismos ao mesmo tempo que enchendo-se de dúvidas e perguntas, sedentas na busca de uma orientação que aponte pelo menos alguns caminhos nos quais possam exercer o seu direito de escolha. E nada é tão fundamental para o exercício da plenitude do que a liberdade de escolha acompanhada da responsabilidade das opções escolhidas. Esta afirmativa entretanto choca-se de frente com a realidade contemporânea de uma sociedade consumista que apresenta a todas as pessoas um modelo de comportamento e atitudes pronto para serem consumidos e seguidos que traduziriam uma referência "equilibrada" de conduta. Assiste-se hoje a um verdadeiro desfile 
de informações e estímulos a respeito de inúmeros temas e assuntos que normatizam uma série de ações que determinam qual o tipo de personalidade que eu tenho a partir da roupa que visto, da comida que compro, etc. Tem-se disponível na atualidade uma verdadeira cardápio de opções, produtos e ofertas nas questões das experiências relativas as experiências do corpo. Qualquer pessoa é bombardeada constantemente com imagens relativas ao corpo e ao movimento.

Estas informações vinculam imagens de corpos jovens, saudáveis, musculosos, associando-se perversamente a marca determinado produto à vinculação da imagem que se procura vender. Em todo o aparato de Meios de comunicação de Massa, qualquer pessoa recebe uma superexposição e uma super-estimulação de seus sentidos, incluindo-se toda a população desde as crianças até aos nossos idosos. Assim, tem-se a impressão que hoje as pessoas possuem uma gama maior de informações a respeito da sua experiência corporal e da vivência da sua sexualidade e isto é um fato. Hoje possui-se uma maior informação a respeito, mas informação não é conhecimento. Assim como informação também não é vivência. E como é diferente a dor que aparece na TV para a dor que o próprio corpo sente.

Vende-se um modelo de corpo e de saúde onde a imensa maioria da população procura adequar-se destinando um número cada vez maior tempo e energia. Porém, as exigências da sociedade contemporânea tornam esta disponibilidade de tempo e energia cada vez menor fazendo com que as pessoas sintam-se frustradas por não alcançarem os objetivos desejados conforme o modelo apresentado. Tal fato é gerador de stress e insatisfação causando uma sucessão de efeitos em cadeia que comprometem a saúde e a suas percepções das vivências do próprio corpo. Neste sentido, o consumismo exacerbado presente na sociedade aparece como substitutos para os desejos não realizados, oferecendo às pessoas os mais diversos produtos disponíveis para encontrar em algo fora de si (externo) a satisfação do seu desejo (que por si só já representa uma necessidade e/ou falta) que seria melhor vivenciado na medida em que fosse percebido como tal e comunicado como tal ao outro. $\mathrm{O}$ outro aqui não como um objeto disponível para a satisfação do meu desejo, mas como alguém no qual assumo o direito legítimo de ser um outro diferente de mim. A história 
humana segue o curso dos desejos, das emoções e das preferências. Como seres vivos somos capazes de viver qualquer modo de vida desde que não nos mate. Pode-se viver a dinâmica da dominação e da submissão, fatos presentes em nossa cultura, e incorporá-los como elementos "naturais" das relações pois faz parte de nossas experiências, ao mesmo tempo que fazem parte também do sofrimento. O ser humano é altamente adaptável às mais diversas e diferenciadas condições de vida, mesmo àquelas que atentam contra a sua integridade e saúde.

Entretanto os indivíduos que encontram-se na fase da maturidade ativa estão, pela própria condição biológica, em desacordo ao modelo apresentado pela mídia e consequentemente encontram-se desobrigados de buscar esta referência. Surge uma oportunidade de vivenciar a própria experiência corporal como forma de aprofundar a consciência de suas próprias sensações. Encontram-se livres para perceberem as suas próprias sensações ao invés de procurarem um modelo consumista externo às suas percepções.

Como se vai trabalhar as questões da experiência sensível se muitas vezes os indivíduos não tem consciência das sensações no próprio corpo? Ferreiro (1986) alerta para o que de mais enganoso existe na percepção do próprio corpo quando constatou a este respeito na construção da aprendizagem da linguagem escrita pela criança ". . . as crianças poderiam ir para escola apenas com uma mão, os olhos e ouvidos. O restante poderia ficar em casa." (p.23). Vê-se que a escola muitas vezes expulsa o corpo dos processos de aprendizagem quando na realidade qualquer ser humano sabe ao tocar uma criança ou ao ser tocado, se esta o rejeita ou acolhe-o e vice-versa. E foi nesta escola que todos nós passamos nosso período de educação formal.

Entretanto parece que o não-toque é uma norma, não assumida mas dissimulada, como forma de manter uma certa formalidade. Parece que muitos esquecem-se que experiências em diversos países com recém-nascidos constataram que a sensibilização epidérmica através do toque na pele estimula a mielinização dos neurônios nas crianças. A experiência corporal e os aspectos relativos ao toque continuam ocupando um papel de destaque na sociedade contemporânea. Ainda é vista como algo a ser controlado por alguns ou que deve ser completamente liberado por outros.

A maturidade ativa, apesar das responsabilidades que o mundo moderno 
exige, encontra-se mais disponível na utilização de seu tempo livre e consequentemente pode prestar mais atenção nas suas sensações no mesmo instante em que, através de uma adequada programação também pode potencializar-se cognitivamente para um processo contínuo de aprendizagem e desenvolvimento pessoal. Talvez possamos reaprender com eles na medida em que através da disponibilização de tempo para a tomada de consciência da história de sensações do próprio corpo tão marcado por anos e anos de labuta e atividade ao mesmo tempo associada a uma potencialização cognitiva percebase que não existe tempo para continuar-se sempre aprendendo.

Em resumo, talvez queiramos concluir com o alerta de que a tomada de consciência das sensações numa vivência do próprio corpo é uma experiência a qual ninguém passa indiferente e assim como possui uma semente potencializadora também possui elementos manipuladores hoje, infelizmente, utilizados por charlatães de plantão que sabem que, nestes tempos modernos as pessoas entregam o seu livre-arbítrio de decisão nas mãos de inescrupulosos que manipulam habilmente a sensação corporal. Perdidos num ambiente de hiper-estimulação visual muitas pessoas vendem a alma ao diabo em troca de algumas sensações corporais que ainda lhes tragam a lembrança de algo que as faça sentirem-se vivas. Lembrando um provérbio chinês: "Aquele que conseguir vivenciar a experiência plena de suas sensações se sentirá como que cavalgando no dorso de um tigre. Uma experiência única . . . porém deverá ter o cuidado de nunca cair de cima dele."

\section{Referências}

1 BRUHNS, H. Conversando sobre o Corpo. São Paulo: Ed. Papyrus, 1984. 2 CHAUCHARD, P. O Cérebro Humano. Lisboa: Publicações EuropaAmérica, 1987.

3 DAMÁSIO, A.R. O Erro de Descartes. São Paulo: Cia. Das Letras, 1996. 4 FERREIRO, E. Psicogênese da Língua Escrita. Porto Alegre: Ed. Artes Médicas, 1986.

5 FONSECA, V. Filogênese da Motricidade. Lisboa: Edições 70, 1982. 6 FOUCAULT, M. Microfísica do Poder. São Paulo: Ed. Graal, 1988.

7 DELGADO, J.M. Emoções. São Paulo: Ed. da USP, 1971. 
8 GARDER, W. O Mundo de Sofia. Rio de Janeiro: Cia. das Letras, 1995. 9 GHIRALDELLI, P. Indicações para o Estudo do Movimento Corporal Humano a partir da Dialética Materialista. Mimeogr., São Paulo: UNICAMP, 1990.

10 GONÇALVES, C. J. Do Corpo que Sente ao Corpo que Aprende. 1997. Dissertação (Mestrado)-CEFID, Universidade Federal de Santa Maria, Santa Maria, RS.

11 GONÇALVES, C. J. Do Corpo que Sente ao Corpo que Comunica. 1998. Dissertação (Mestrado)-PPGEDU-Universidade Federal do Rio Grande do Sul, RS.

12 GONÇALVES, C. J. Ler e Escrever também com o Corpo em Movimento In GUEDES, et al Leitura e escrita \&ndash; compromisso de todas as áreas. Porto Alegre: Ed. UFRGS, 1998.

13 GONÇALVES, C. J. Onde está o Corpo no Processo de Aprender a Avaliar? In PAIVA M.G, Avaliação: novos paradigmas, novas tendências. Porto Alegre: Ed. Mercado Aberto, 2000.

14 HUMPREY, N. Uma história da Mente. São Paulo: Ed. Campus, 1995.

15 LOWEN, A. Prazer: uma abordagem criativa da vida. São Paulo: Ed. Summus, 1998.

16 MATURANA, H. El Árbore del Conocimiento. Buenos Aires: Ed. Piados, 1993.

17 MERLAU-PONTY, M. Fenomenologia da Percepção. São Paulo: Freitas Bastos, 1971.

18 MONTAGU, A. Tocar: o significado humano da pele. São Paulo: Summus Editorial, 1988.

19 MORIN, E. O método - I. Lisboa: Edições 70, 1997.

20 NAFFAH, A. O Inconsciente como Potência Subversiva. São Paulo: Ed. Escuta, 1990.

21 PIAGET, J. Os Pensadores. São Paulo: Ed. Abril Cultural, 1978.

22 PINKER, S. Language Instinct. MIT-PRESS, 1994.

23 PINKER, A. Fundamentos da Neurociência. São Paulo: Print Hall do Brasil, 1997.

24 RESTREPO, L. C. O Direito à Ternura. Petrópolis: Ed. Vozes, 1997. 
25 SAGAN, C. O Mundo Assombrado pelos Demônios. São Paulo: Cia. das Letras, 1996.

26 SANTIN, S. Ed. Física Outros Caminhos. Ijuí: UNIJUI, 1987.

27 SANTIN, S. Ed. Física Temas Pedagógicos. Ijuí: UNIJUÍ, 1993.

28 SANTOS, M. A Natureza do Espaço. São Paulo: Hiuatec, 1994. 